\title{
Previously diagnosed psychiatric illness among inhabitants of common lodging houses
}

\author{
N J SHANKS \\ From the Department of General Practice, University of Sheffield Medical School, Department of Community \\ Medicine, Beech Hill Road, Sheffield S10 2RX, United Kingdom.
}

\section{ABSTRACT}

Study objective: The aim of the study was to determine the characteristics of the homeless population and their previously diagnosed psychiatric illnesses in a well defined inner city area.

Design: The study involved a one in 10 sequential sample collected over three years.

Setting: Hostels and day care centres for the homeless in Manchester.

Participants: 420 homeless people were interviewed; 17 were excluded because of lack of rapport. Results: The majority were single middle aged catholic males who left school early and were unemployed; $48.7 \%$ had a history of alcoholism, $38.5 \%$ of diagnosed psychiatric illness, and $22.6 \%$ of psychiatric inpatient treatment. Only $21 \%$ of those with psychiatric diagnoses were being treated or followed up at the time of study. There was a strong association between criminal behaviour and previous admission to a psychiatric unit.

Conclusions: There is a high incidence of psychiatric illness among the homeless, particularly among those originating from the locality studied. They tend to be geographically stable and therefore accessible to the provision of facilities for continuing care.

There has been renewed interest in the plight of the homeless and rootless. ${ }^{1-3}$ Recent reports suggest that they now number in excess of 100000 and that they are usually single, middle aged, unemployed males commonly suffering from psychiatric disorders and social ostracism. ${ }^{4-7}$ Epidemiological studies of psychiatric illness have consistently found high rates among those of low socioeconomic status ${ }^{8-10}$ and in city centres where vagrants tend to migrate. ${ }^{11} 12$ In New York City, where there are 30000 homeless on the streets, one third of whom are discharged psychiatric patients, ${ }^{13}$ violence has reached unprecedented levels. ${ }^{14}$ Levinson $^{15}$ examined the psychological features of shelter inhabitants and concluded that "they are emotionally immature, are depressed, and have great difficulty in adjusting to the world".

It is apparent that the homeless are not a homogeneous group and rehabilitation strategies will depend on the availability of resources allocated to medical and social services. The problem is enhanced by a general shortage of low cost accommodation. For example, in London the increased use of temporary accommodation is matched by a fall in the supply of local authority housing.
Edwards et $a l^{16}$ reported that $39 \%$ of their vagrant alcoholic sample had been confined in a psychiatric institution. ${ }^{16}$ A similar figure of $34 \%$ was reported by Crossley and Denmark. ${ }^{17}$ Lodge Patch ${ }^{18}$ reported on the demographic features of 123 randomly selected homeless men from Salvation Army hostels: $15 \%$ were schizophrenic, $21 \%$ were alcoholic, $10 \%$ were mentally subnormal, $50 \%$ had personality disorders and $23 \%$ admitted to having been psychiatric inpatients. Priest ${ }^{19}$ reported on a random group of homeless males from an Edinburgh common lodging house: $\mathbf{7 5} \cdot 3 \%$ displayed some psychiatric morbidity, $32 \%$ were overtly schizophrenic, $18 \cdot 2 \%$ had personality disorders and $9 \cdot 1 \%$ were mentally subnormal.

Both Lodge Patch and Priest experienced considerable difficulty in sampling this population. Other researchers have reported the readiness with which vagrants will attempt to deceive when being interviewed. ${ }^{20-24}$ There are difficulties in drawing conclusions from such studies which are compounded by the fact that they survey only a limited number of lodging houses within a well defined geographical area. Certain types of accommodation vary in their quality and content and will therefore tend to 
accommodate different types of homeless individuals.

This study sought to investigate the problems of "single homelessness" which are substantially different from the much larger problems of homeless families. It is apparent that any interviewer who does not establish a firm relationship with this type of group is unlikely to achieve consistent results. Indeed it has been shown conclusively, by test and retest, that reliable data cannot be gained from the homeless population by an unknown observer and can only be obtained once rapport has been established. ${ }^{24}$ This present study was designed to determine the characteristics of the total homeless population and their previously diagnosed psychiatric illness in a well defined inner city area. However, because the group studied consisted only of homeless people who had previously sought out medical help, both physical and psychiatric illnesses are likely to be overrepresented.

\section{Methods}

The Medical Practices Committee agreed in 1977 that the Manchester Family Practitioner Committee could establish a limited list practice to deal solely with the homeless, who were thought to number 2500 . I was granted a full time Research Fellowship and was attached to the staff of the Area Medical Office with the remit to study both the medical problems of homelessness and the organisation of primary care. ${ }^{67}$ Initially, medical care was provided for one night shelter, a converted Victorian school, but the service quickly expanded to cover the whole of Manchester including visits to eight hostels or lodging houses, two voluntary societies and two day centres. There was no central surgery and all consultations were conducted in the hostels themselves to ensure easy accessibility for residents. There was no appointment system. The consultations were held at the times when a large number of the residents could be expected to be present.

Over a period of three years a study was made of the demographic features of every tenth homeless person who consulted the author (as a medical officer) and with whom he had the sort of rapport which had previously been shown to provide stable data.$^{24}$ No person who fulfilled the criteria for admission to the sample was excluded from the study.

All the homeless interviewed were approached in an identical manner. Cooperation was voluntary, without reward. All interviews were conducted in rooms available for medical purposes in common lodging houses in Manchester. All the lodging houses in Manchester were sampled, thus obtaining as complete a picture of homelessness as was possible for the city. The interviewees were asked if they would answer some questions for purposes of medical research. It was made clear that the information would be treated confidentially and would not be made available to the "authorities" or to one another.

Each interview consisted of $\mathbf{4 0}$ questions and each patient was questioned singly. No time limit was set for completion of the questionnaire, which was filled in by the interviewer in the presence of his subject. Most of the questions demanded the answer "yes" or "no", except for those that involved time spans. The questions covered age, nationality, religion, standard of education, whether the subjects had been in various institutions (for example, childhood, mental or penal), medical and social history, family history and length of stay in lodging houses. No prebriefing was attempted of the inmates of the lodging houses where the interviews took place.

It should be emphasised that this study addressed itself to previously diagnosed psychiatric illness and is not an assessment of existing psychiatric morbidity. Where history of previously diagnosed psychiatric illness was obtained the diagnosis was confirmed by examination of psychiatric medical records $(84 \%)$ and where necessary by referral to a consultant psychiatrist.

\section{Results}

Four hundred and twenty three homeless people were interviewed. Seventeen were excluded from the study because of lack of rapport. The sample provided a wide age range ( 19 to 77 years) with a mean of 48 years.? The demographic details are shown in table 1.

Table 1 Demographic features of 423 homeless men

\begin{tabular}{lrr}
\hline Demographic feature & $n$ & $\%$ \\
\hline Male & 410 & $96 \cdot 9$ \\
Female & 13 & $3 \cdot 1$ \\
Age $>60$ years & 77 & $18 \cdot 2$ \\
Age $>70$ years & 14 & $3 \cdot 5$ \\
Married & & $3 \cdot 5$ \\
Divorced & & $40 \cdot 2$ \\
Widowed & 4 \\
Single & 220 & 52 \\
$>5$ Siblings & & 40 \\
Contact with relatives & 195 & $45 \cdot 4$ \\
Other family members destitute & 27 & $6 \cdot 4$ \\
Illiterate & 65 & $15 \cdot 4$ \\
School leaving age < 14 years & 244 & $57 \cdot 7$ \\
Higher education & 12 & $2 \cdot 8$ \\
Roman Catholic & 226 & $53 \cdot 4$ \\
\end{tabular}

Sixty nine persons $(16.3 \%)$ had been in a childhood institution and $220(52.0 \%)$ were brought up in an atmosphere of considerable parental disharmony. The average length of stay in their present hostel accommodation was 10.2 months. The average length 
of time of residence in hostels was nearly two years (20.7 months).

Despite the fact that the majority of this population were of working age only $24(5.7 \%)$ were employed. The remaining $399(94.3 \%)$ were out of work and of these only $5 \%$ had been employed in the previous month; $25 \%$ had been unemployed for five years or more. The social class of the subjects by occupation tended to be lower than that of their fathers. Those who had psychiatric illnesses seemed to have less chance of being in employment, although this trend did not reach statistical significance $(p>0 \cdot 2)$.

Two hundred and six $(48.7 \%)$ had a history of alcoholism and $167(39.5 \%)$ reported that there was a family history of alcoholism. Eleven $(6 \cdot 7 \%)$ had attempted to commit suicide. Seven (4.3\%) had made multiple attempts. One hundred and sixty three $(38.5 \%)$ had a history of diagnosed psychiatric illness and $95(22.6 \%)$ had been psychiatric inpatients. Fifty eight $(13.5 \%)$ had a family history of psychiatric illness. Only $35(21.0 \%)$ of those with psychiatric diagnosis were being treated or followed up at the time of the survey. All information was corroborated with consultation of the patients' notes. The figure shows the interaction between psychiatric illness, alcoholism and drug abuse among the sample population.

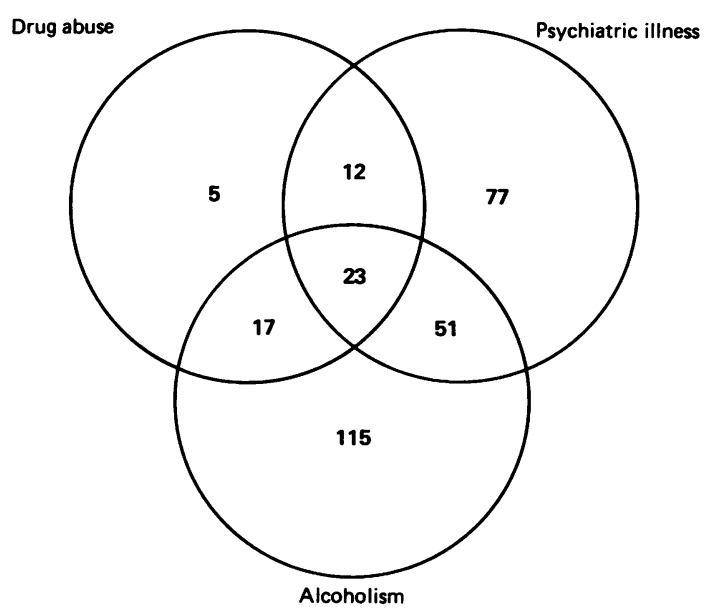

Figure Ven diagram showing interaction between psychiatric illness, alcoholism and drug abuse among hostel dwellers.

Table 2 shows the various categories of diagnosed psychiatric illness. These findings are similar to those reported by other researchers. ${ }^{18} 19$ The residents of the lodging houses who had themselves originated in Manchester were more likely to have a psychiatric history than those who had originated elsewhere (see table 3). Those who were alcoholics were no more likely to be admitted to psychiatric units than those who were not $(p>0.7)$. It may be that because of the management problems associated with homeless alcoholics there is an unwillingness to accept them into psychiatric care. $^{2526}$

Table 2 Categories of diagnosed psychiatric illness

\begin{tabular}{lcc}
\hline Diagnostic type of psychiatric illness & $n$ & $\%$ \\
\hline Bipolar affective illness & 67 & $41 \cdot 2$ \\
Unipolar depressive & 31 & $19 \cdot 0$ \\
Other neurotic conditions & 18 & $11 \cdot 0$ \\
Personality disorder & 32 & $19 \cdot 6$ \\
Mental subnormality & 7 & $4 \cdot 3$ \\
Pre-senile dementia & 2 & $1 \cdot 2$ \\
Senile dementia & 4 & $2 \cdot 5$ \\
Boxers encephalopathy & 2 & $1 \cdot 2$ \\
Total & 163 & 100
\end{tabular}

In addition $206(48.7 \%)$ were alcoholics $57(35 \%)$ were regular drug abusers

Table 3 Cross tabulation of psychiatric history with place of origin

$\frac{\text { Psychiatric history }}{\text { Yes No }}$

\begin{tabular}{lrcrrrr}
$\begin{array}{l}\text { Place of } \\
\text { origin }\end{array}$ & $n$ & $(\%)$ & $n$ & $(\%)$ & \multicolumn{1}{c}{ Total } & $(\%)$ \\
\hline Manchester & 53 & $(52 \cdot 0)$ & 49 & $(48 \cdot 0)$ & 102 & $(24 \cdot 1)$ \\
Scotland & 25 & $(29 \cdot 4)$ & 60 & $(70 \cdot 6)$ & 85 & $(20 \cdot 1)$ \\
Eire & 30 & $(30 \cdot 3)$ & 69 & $(69 \cdot 4)$ & 99 & $(23 \cdot 4)$ \\
Rest of England & 38 & $(40 \cdot 4)$ & 56 & $(59 \cdot 6)$ & 94 & $(22 \cdot 2)$ \\
Others & 17 & $(39 \cdot 5)$ & 26 & $(60 \cdot 5)$ & 43 & $(10 \cdot 2)$ \\
Total & 163 & $(38 \cdot 5)$ & 260 & $(61 \cdot 5)$ & 423 & $(100 \cdot 0)$ \\
\hline
\end{tabular}

Manchester $v$ elsewhere: $\chi^{2}=13.49, \mathrm{DF}=3, \mathrm{p}<0.004$.

There was a strong association between criminal behaviour and previous admission to a psychiatric unit $(p<0.01$, see table 4$)$. A high prevalence of serious mental illness among the homeless and those in prison has been reported. 2728

Table 4 Cross tabulation of psychiatric unit and criminal report

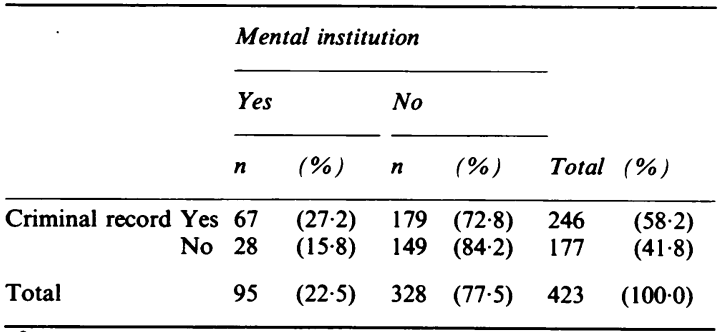

$\chi^{2}=6.91, \mathrm{DF}=1, \mathrm{p}<0.01$ 
Psychiatric illness was more common among those who had been brought up in a children's home $(p<0.01)$. Moreover, there was a statistically significant increase in admissions to mental hospitals among those who had been in a children's home $(p<0.03)$. The higher incidence of previously diagnosed psychiatric illness in former inmates of childhood institutions might simply reflect childhood psychiatric morbidity; conversely it might reflect an adverse effect on psychological development. The present data do not allow these suggestions to be clarified.

\section{Discussion}

For the reason that this study is confined to the homeless population of a single city the results may not be typical of the homeless population as a whole, but they can to some extent be extrapolated to the whole of this disadvantaged, difficult and defensive subgroup. The overall findings confirm a general impression of this population based on experience as a medical officer of 30000 or more contacts. Because of the heterogeneity of this group, such a study will differ in certain observations from surveys conducted elsewhere and at a different point of time, although Priest ${ }^{4}$ was able to show strong similarities between inhabitants of skid row in a USA-UK comparison. However, certain findings, such as the high incidence of Roman Catholics are difficult to explain.

It has been a policy since the Mental Health Act (1959) in health and social services to reduce the number of those in institutional care and encourage people with special needs who require some form of temporary or permanent support to live in a noninstitutionalised setting in the community. This philosophy is acceptable only if adequate support from the local authorities is forthcoming. Unfortunately, many patients who had been institutionalised for long periods have followed a downward spiral, on release, to the common lodging house. Furthermore, there is a high suicide rate in schizophrenic patients after hospital discharge ${ }^{29}$ and social workers with ill defined responsibilities ${ }^{30}$ are unsuitable to supervise the mentally ill. ${ }^{31}$ Previous surveys ${ }^{1627}$ have shown a high degree of social and psychiatric morbidity among the homeless. However, the demand on services was such that nearly two thirds of the mentally ill, three quarters of the alcoholics, and half of the physically handicapped new cases did not receive medical treatment and were not referred elsewhere. Since 1954 the number of long stay patients in psychiatric institutions in England and Wales has halved. Yet, despite statutory obligations towards the vulnerable homeless (Health and Public Services Act 1968), few have been accommodated by local authorities. The remainder live in the dwindling number of common lodging houses, soon to shut reception centres, and substandard rented accommodation-some of which is so bad that many prefer to sleep rough. ${ }^{32}$

Over half of the sample who were English (51.5\%) were diagnosed as mentally ill. What is especially noteworthy is the very high incidence of mental illness among those originating from Manchester. The Manchester cohort contains people discharged from local mental hospitals who still may be too ill to move away. The high prevalence of mental illness, particularly schizophrenia $(30.1 \%)$, is in accordance with the predictions one would make from epidemiological studies, especially those revealing high rates in association with social class and city centres. Although the figure for mental illness is high $(38.5 \%)$ it obviously accounts only for a minority who adopt this lifestyle. A similar observation has been made among a vagrant population in Norway. ${ }^{33}$

Homeless men live without the privacy, possessions or personal contacts which are, to the majority of society, the basic requirements of a home. It is probable that such a sojourn is often one of the outcomes of personality defects which determine the incapacity to develop close personal relationships, a stable marriage or a consistent role in society. The origin of this inability can often be seen in childhood, when the benefits of a stable family life have been eroded. They are likely to be the product of an earlier generation's social and parental attitudes and/or, sometimes, broken homes. The ensuing restlessness, irritability and profound difficulty in forming rewarding emotional contact may not only set them drifting but also predispose them to soothe their malaise by drinking. Initially, alcohol may not necessarily be an anaesthetic but, perhaps like "a smoke", it is one of the few pleasures available until it becomes uncontrolled.

The ultimate product is a man without a home who is, at any rate for the time being, incapable of sustaining one, and who becomes incapable of any other way of life than that of circulating through prisons, mental hospitals and doss houses. Even in a well population, changing home is known to be one of the most unsettling of life's events. ${ }^{34}$ The isolation of these men is evident from their celibacy $(52.0 \%)$, or broken marriages $(40.2 \%)$, and their rejection of relatives $(54 \cdot 6 \%)$.

The provision of rehabilitation facilities for mentally ill patients in the community is inadequate. Leach and Wing ${ }^{35}$ reported on how the effectiveness of the St Mungo's Trust for helping destitute men was enhanced by the use of action research techniques where research findings were employed to modify the original project. They discovered that those suitable 
for placement in a rehabilitation scheme were more effectively assessed from a night shelter than a soup kitchen. Furthermore they described an "enabling model" of rehabilitation, with contact services on the street, progressing on to chains of housing and vocational opportunities at spaced levels, with the provision of facilities for those who cannot ascend from any particular level.

There is increasing concern about the discharge of patients from long stay hospital care into a community with a marked lack of aftercare facilities, since resettlement is not achievable in the absence of back up services in the community. ${ }^{1636}$ Many of the mentally ill represent failures of community care. One of the reasons often given for the failure to provide resources for the care of the homeless population is that it is in fact a vagrant one, with a high degree of geographical mobility. However, the results of this study refute this unchallenged assumption. The average length of stay in hostels is $\mathbf{2 0 . 7}$ months and in many cases much longer. Although the inmates are homeless they are geographically stable, thus suggesting that many could be accessible to efforts to ameliorate their suffering on a long term basis.

Certain types of behaviour which may be unacceptable and considered abnormal in middle class society are perceived (or ignored) as normal among inmates of common lodging houses. One is made quickly aware of this by being confronted by their bizarre behaviour. The residents appear to have a high tolerance of abnormal behaviour, although sometimes condemn other inmates: for as one old man remarked to me, with a glint in his eye "you have to be a nutter to stay here".

\section{References}

${ }^{1}$ Shanks NJ. Medical morbidity of the homeless. $J$ Epidemiol Community Health 1988; 42: 182-5.

${ }^{2}$ Featherstone P, Ashmore C. Health surveillance project among single homeless men in Bristol. J R Coll Gen Pract 1988; 38: 353-5.

${ }^{3}$ Powell PV. Primary health care for the single homeless. $\mathrm{Br}$ Med J 1988; 297: 84-5.

${ }^{4}$ Priest RG. Homeless men. A USA-UK comparison. Proc $R$ Soc Med 1970; 63: 441-5.

${ }^{5}$ Shanks NJ. Demographic features of inmates of common lodging houses. Manchester: University of Manchester, 1981. MScThesis.

${ }^{6}$ Shanks NJ. Medical care for the homeless. Br Med J 1982; 284: 1679-80.

${ }^{7}$ Shanks NJ. Medical provision for the homeless in Manchester. J R Coll Gen Pract 1983; 33: 40-41.

${ }^{8}$ Hollingshead AB, Redlich FR. Social class and mental illness. New York: John Wiley, 1958.

${ }^{9}$ Dohrenwend BP, Dohrenwend BS. The problems of validity in field studies of psychological disorder. $J$ Abnorm Psychol 1965; 70: 52-69.
${ }^{10}$ Gillis LS. Psychiatric disturbance and alcoholism in the coloured people of the Cape Peninsula. Groote Schuur Hospital and University of Cape Town: Department of Psychiatry, 1965.

11 Faris REL, Dunham HW. London's skid row. Lancet 1960; i: $249-52$.

${ }^{12}$ Hare ED. Family setting and the urban distribution of schizophrenia. J Ment Sci 1965; 102: 753-60.

${ }^{13}$ Cheadle J, Ditchfield J. Sentencing mentally ill offenders. London: Home Office Research and Planning Unit, 1982.

${ }^{14}$ Brickner PW, Scharer LK, Conanan B, Elvy A, Savarese $\mathrm{M}$, eds. Health care of homeless people. New York: Springer, 1985.

${ }^{15}$ Levison BM. Some aspects of the personality of the native born white homeless man as revealed by the Rorschach. Psychiatr Q Suppl 1958; 32: 278-86.

${ }^{16}$ Edwards G, Hawker A. Census of a reception centre. Br J Psychiatry 1968; 114: 1031-9.

${ }^{17}$ Crossley B, Denmark JC. Community care: A study of the psychiatric morbidity of a Salvation Army hostel. Br J Sociol 1969; 4: 433-40.

${ }^{18}$ Lodge Patch IC. Homeless men in London. Br J Psychiatry 1971; 118: 313-7.

${ }^{19}$ Priest RG. The homeless person and the psychiatric services. An Edinburgh survey. Br J Psychiatry 1978; 125: 128-36.

${ }^{20}$ Laubach FC. Why there are vagrants: a study based upon an examination of one hundred men. New York: New York University, 1916. PhD Thesis.

${ }^{21}$ Anderson N. The hobo: The sociology of the homeless man. Chicago: University of Chicago Press, 1923.

22 Edge W. The main stem. New York: Vanguard, 1972.

${ }^{23}$ Gentry C. The madames of San Francisco. New York: Doubleday, 1964: 206.

${ }^{24}$ Shanks NJ. Consistency of data collected from inmates of a common lodging house. J Epidemiol Community Health 1981; 35: 133-4.

${ }^{25}$ Cook T. Vagrant alcoholics. London: Trinity Press, 1975.

26 Jeffrey R. Attitude towards deviant patients in casualty departments. Sociol Health Illness 1979; 1: 90-107.

27 Tidmarsh D, Wood S. Psychiatric aspects of definition. In: Wing JK, Hayley A, eds. Evaluating a community psychiatric service. Oxford: Oxford University Press, 1972.

${ }^{28}$ Leach J, Wing JK. Helping destitute men. London: Tavistock Publications, 1980.

${ }^{29}$ CHAR (Campaign for the Homeless and Roofless). Health care for the single homeless. London: CHAR, 1981.

${ }^{30}$ Anonymous. Mental health of the community A report of the Richmond Fellowship Inquiry. London: Richmond Fellowship Press, 1983.

${ }^{31}$ Barclay PM (Chairman). Social workers, their role and tasks. London: Bedford Square Press, 1982.

32 Timmins N. Vagrants prefer streets to hostels. The Times Supplement 1984. Mar 11.

${ }^{33}$ Noreik K. Hospitalised psychoses among wandering people in Norway. Acta Psychiatr Scand 1965; 41: 157-76.

34 Brown GW, Harris J. Social origins of depression. London, Tavistock Publications, 1978.

${ }^{35}$ Leach J, Wing JK. The effectiveness of a service for helping destitute men. Br J Psychiatry 1978; 113: 481-92.

${ }^{36}$ Page P. Camberwell Reception Centre. New Society 1965; 134: $18-21$. 